San Jose State University

SJSU ScholarWorks

Fall 2021

\title{
Rip Curl: Community Activism for the Coast (The UX Phase, Rip Curl and Sustainability, The UI Phase)
}

John Delacruz

San Jose State University, john.delacruz@sjsu.edu

Follow this and additional works at: https://scholarworks.sjsu.edu/sustainable-futures-prompts

Part of the Computer-Aided Engineering and Design Commons, Industrial and Product Design Commons, and the Sustainability Commons

\section{MLA Citation}

Delacruz, John. "Rip Curl: Community Activism for the Coast (The UX Phase, Rip Curl and Sustainability, The UI Phase)." Sustainable Futures, 2021. doi:10.31979/SF.2021.001.

This Assignment is brought to you for free and open access by the Sustainable Futures at SJSU ScholarWorks. It has been accepted for inclusion in Assignment Prompts by an authorized administrator of SJSU ScholarWorks. For more information, please contact scholarworks@sjsu.edu. 
Faculty Name: John Delacruz

Department: Journalism and Mass Communications

Email: john.delacruz@sjsu.edu

Semester taught assignment (if applicable): Fall 2021

Course Title (if applicable): ADV 132 UX and UI Design for Advertising

Assignment Title: Rip Curl: Community Activism for the Coast (The UX Phase, Rip Curl and Sustainability, The UI Phase)

Creative Commons license: Attribution-ShareAlike 4.0 International (CC BY-SA 4.0)

Context: ADV 132 enables students to explore the craft and process of user experience and user interface design. They develop their skills within the context of a specific brief. The aim is to offer students the opportunity to immerse themselves in a particular problem and come up with creative solutions that will come to life on digital media platforms.

The assignment is scaled. It is a ten-week assignment divided into three sections. Each section builds on the other.

Students begin the UX Design research process determining the nature of their product, target users an, of course, the subject matter itself. I have underscored the importance of the subject by including an in-depth analysis of the problem. And then there is the final stage - UI Design. This is where the digital product is designed and built.

This semester's assignment focused around ocean sustainability. The client was Rip Curl and the aim was to educate and activate users on sustainability as it impacts the coastal regions.

The three phases of the assignment are supported by individual modules on the course Canvas site. Here students find resources, links and other materials that support each phase of the project. This Spark page is a primer for students so they can get the most out of the modules: https://spark.adobe.com/page/S8LFyE1Wx4e6b/

Under assignment text you will find links to the assignment briefs as Spark Pages. There is also a link to the brief's section in my teaching portfolio. A showcase of student work will be on there when the semester ends, so check back after December 15. I have also pasted the assignment text for the purposes of this exercise. 


\section{The Assignments}

The UX and UI Phases: https://spark.adobe.com/page/qitp9wD1KXgtK/

Rip Curl and Sustainability: https://spark.adobe.com/page/mhamgbt9sFcPb/

\section{Rip Curl Community Activism for the Coast}

\section{A LITTLE BIT OF RIP CURLING BACKGROUND}

Rip Curl remains a company built by surfers for surfers, and they've been market leaders in surfing for over 50 years. They endeavor to make the best products, run the best events, support the best athletes, deliver the best customer service, communicate the best brand message and have the best crew of people. This helps Rip Curl hold a vision of being regarded as The Ultimate Surfing Company.

\section{THE THEME: COMMUNITY ACTIVISM FOR THE COAST}

Since its founding, Rip Curl has actively supported groups and issues relevant to its local communities, particularly the maintenance of coastal environments. How can you encourage the larger public to be aware of, contribute to, or actively support the maintenance of coastal environments?

\section{THE CHALLENGE:}

Develop a third-party mobile app that encourages local coastal communities to take action and help preserve their coastal environments, through one or more of these example functions:

- Engage the greater community to volunteer in preservation efforts

- Provide a way to educate others about coastal habitats, why they matter, and how they can be maintained 
- Promote advocacy for more sustainable ways to produce, recycle, and reuse Gamify active awareness and activism such as promotion, donations, or volunteerism

- Elevate news, companies, organizations, and/or individuals focused on this progress

- Integrate virtual or augmented reality to connect preservation outcomes with visual impact

- Encourage social media sharing to create momentum

\section{THE USERS}

This audience includes Rip Curl surfers and fans, but does not necessarily focus on them, so design for a target market with varying levels of awareness of coastal issues and technological prowess.

\section{REFERENCE \\ Rip Curl Planet}

\section{YOUR TASK}

Over the following weeks you will build foundational knowledge, identify insights, develop a deep understand of and empathy with your users, and create a product that delivers the requirements of the brief above.

You will begin the project by focusing on the human centered design approach, understanding your users' needs and their relationship with the issues raised by the client are paramount to creating a useful and relevant product.

You will need to build a digital product as required by the brief. You may choose to design a website or a mobile app. Perhaps a game or other experience. Your product must be targeted at a specific user group as identified in the brief. By the end of the course you will prototype the platform and you will document your process from initial user research all the way to the end-point.

Along the way, you will learn to conduct user research and identify useful insights about your target and the product, you will learn to create personas that help you navigate the project, you will learn to ideate and wireframe. And then you will learn about building prototypes using Adobe XD, Figma and other tools, about creating augmented reality 
experiences using Adobe Aero, and documenting the UX and UI process by using Adobe Spark.

\section{THE DELIVERABLES}

Use Adobe Spark Page to create a document detailing the Human Centered Design Research stages of your project. Include the following:

1. Ethnographic Research: Write-up your findings and insights that emerged from interviewing, fly-on-the-wall observation, contextual inquiry, walk-a-mile immersion.

2. User Personas: 1 set of minimum 5 user persona profiles

3. Problem Framing: Present a Problem Tree Analysis

4. Concept Ideation: Thumbnail sketches, a creative matrix and an alternative world You will need to link to your Adobe Spark Page in the Canvas submission box and upload to the \#UXUI Slack Channel. Comment on the other teams' projects in a supportive manner.

DEADLINE: OCTOBER 14, 2021

\#2: The UI Phase Deliverables:

Create a Spark Page detailing the UI Design phase of your project. Include the following:

1. Wireframes: You should present lo-fi renditions, ideally thumbnails, detailing the messy process of figuring out a user journey. Also include the hi-fi iterations.

2. User Journey: Remember your personas? Take one of them through your product.

3. Style Guide: Present a style guide detailing typography, colors, iconography, UX writing examples, art direction and any other system components that are necessary

4. Prototype: Create a prototype on Adobe XD or Figma, and maybe an AR feature on Adobe Aero.

You will need to post your Spark Page in the Canvas submission box and upload to the \#UXUI Slack Channel. Comment supportively on the other teams' projects.

DEADLINE: DECEMBER 02, 2021 


\title{
Rip Curl, Sustainability and User Experience
}

\author{
Let's Make Sense of Stuff
}

The brief you have been assigned to solve relates directly to themes of sustainability, environmental justice, and the health of our oceans and coastlines. The UX Research Process requires breadth and depth of understanding of key issues pertaining to the product or experience you have been asked to design.

In order to help you make sense of all this information I would like you to, individually, reflect on the research you have conducted as a team in relation to sustainability and ocean health.

The Sustainability Module is your starting point. From here you will broaden your research and answer questions related to sustainability and the relationship with Rip Curl and the product you will design.

Reflecting on your research will involve bringing together your sources, insights and reference points:

- First of all, cover all the different sections highlighted in the module folder.

- Read this info leaflet from the UN and consider it in terms of your assignment. How can your product or experience respond to this information and goals.

- Think of how sustainability will fit into your product design - as content, as supporting material, as inspiration.

- Reflect on sustainability in terms of User Experience - are there apps or other digital products you have found to be inspirational, or maybe they are bad examples of UX Design.

- Present this information in a Spark Page.

- Include images, videos (if you have any) and cite your reference sources.

- Aim for depth in analysis and breadth in content.

- Ensure it is substantial in terms of content (no word count, use your initiative).

Submit your Spark link to Canvas by the due date and share on Slack as well. 
